\section{OP0262 FACTORS ASSOCIATED WITH ACUTE ANTERIOR UVEITIS IN PATIENTS WITH AXIAL SPONDYLOARTHRITIS: ANALYSIS OF THE BSRBR-AS REGISTER DATABASE}

Mohammad H. Derakhshan ${ }^{1}$, Linda Dean ${ }^{2}$, Gareth T. Jones ${ }^{2}$, Gary J. Macfarlane ${ }^{2}$, Stefan Siebert ${ }^{1}$, Karl Gaffney ${ }^{3} .{ }^{1}$ University of Glasgow, Institute of Infection, Immunity and Inflammation, Glasgow, United Kingdom; ${ }^{2}$ University of Aberdeen, Epidemiology Group, Aberdeen, United Kingdom; ${ }^{3}$ Norfolk and Norwich University Hospital, Rheumatology Department, Norwich, United Kingdom

Background: Acute anterior uveitis (AAU) is one of the key extra-articular manifestations in axial spondyloarthritis (axSpA). The presence of AAU may influence the decision to start and the choice of biological therapy.

Objectives: To examine the factors associated with AAU in patients with axSpA in the British Society for Rheumatology Biologics Register in Ankylosing Spondylitis (BSRBR-AS)

Methods: Clinical and patients-reported outcomes of 2420 patients with axSpA from 83 rheumatology centres in the United Kingdom were collected as part of the BSRBR-AS. Patients with AAU diagnosed by an ophthalmologist were compared to those without AAU in relation to demographic and lifestyle factors. The associations were analysed using univariable and multivariable logistic regression models, considering necessary interaction terms and sensitivity analyses.

Results: $568(23.5 \%)$ patients in the cohort had at least one episode of AAU. The male/female ratio was 2.0:1 and group's median (IQR) age was $51(41-61)$ years. Factors associated with higher odds of AAU in univariable analyses were HLA-B27 positivity [OR $2.32(95 \% \mathrm{Cl}: 1.66-3.23)$ ], university degree [OR 1.44 (95\% Cl: $1.53-1.79)]$, age [OR (per year) $1.02(95 \% \mathrm{Cl}: 1.01-1.03)]$ and axSpA disease duration [OR (per year) $1.02(95 \% \mathrm{Cl}: 1.02-1.03)]$. Ever-smoking was inversely associated with AAU [(OR $0.71(95 \% \mathrm{Cl}: 0.59-0.89)]$. Ever-alcohol drinking $(p=0.213)$, BMI $(p=0.325)$ and gender $(p=0.317)$ did not show any associations.

In multivariable analysis, the magnitude of associations remained significant for HLA-B27 positivity, age, and axSpA disease duration, as did the inverse association with smoking (see Table). Analysis restricted to patients with inflammatory bowel disease did not alter the relationship between AAU and the above risk factors.

Table 1. Factors associational with $\mathrm{AAU}$ in axSpA, multivariable analysis

\begin{tabular}{lccccc}
\hline & Wald & df & $\begin{array}{c}\text { P } \\
\text { value }\end{array}$ & OR & $\begin{array}{c}95 \% \text { Cl for } \\
\text { OR }\end{array}$ \\
\hline Ever Smoking (vs never) & 9.76 & 1 & 0.002 & 0.614 & $0.452-0.834$ \\
University Degree (vs lower) & 2.27 & 1 & 0.132 & 1.325 & $0.919-1.912$ \\
HLA-B27 positive (vs & 21.12 & 1 & $<0.001$ & 2.399 & $1.652-3.484$ \\
negative) & & & & & \\
Age & 17.25 & 1 & $<0.001$ & 1.038 & $1.020-1.056$ \\
AxSpA Disease Duration & 15.77 & 1 & $<0.001$ & 1.093 & $1.046-1.142$ \\
\hline
\end{tabular}

Conclusion: The odds of having a diagnosis of AAU is high in axSpA patients with positive HLA-B27, and longer disease duration (having controlled for age). The negative association with smoking in this large cohort contrasts with previous published data and warrants further evaluation.

Acknowledgement: British Society of Rheumatology

Disclosure of Interests: Mohammad H. Derakhshan: None declared, Linda Dean: None declared, Gareth T. Jones Grant/research support from: Have received research grants (not current) from Abbvie and Pfizer.

Have received research grants (not current) from the British Society for Rheumatology, who received the funds from Abbive, Pfizer and UCB.

Have received research grant (current) from the British Society for Rheumatology, who received the funds from Celgene., Gary J. Macfarlane Grant/research support from: Have received research grants (not current) from Abbvie and Pfizer.

Have received research grants (not current) from the British Society for Rheumatology, who received the funds from Abbive, Pfizer and UCB.

Have received research grant (current) from the British Society for Rheumatology, who received the funds from Celgene., Stefan Siebert Grant/research support from: AbbVie, Novartis, Pfizer, Janssen, BMS, Celgene, UCB, and Boehringer Ingelheim, Consultant for: AbbVie, UCB, Pfizer, Janssen, Boehringer Ingelheim, Celgene, and Novartis, Speakers bureau: AbbVie, UCB, Pfizer, Janssen, Boehringer Ingelheim, Celgene, and Novartis, Karl Gaffney Grant/research support from: Abbvie, Pfizer, Consultant for: Abbvie, Lilly, Novartis, UCB, Speakers bureau: Abbvie, Biogen, Gilead, Lilly, Novartis, UCB

DOI: 10.1136/annrheumdis-2019-eular.2859

\section{OP0263 \\ HYDROXYCHLOROQUINE DOSING IN PATIENTS WITH RHEUMATIC DISEASE ACROSS THE U.S.: DATA FROM THE RHEUMATOLOGY INFORMATICS SYSTEM FOR EFFECTIVENESS (RISE) REGISTRY}

Zara Izadi ${ }^{1}$, Milena Gianfrancesco ${ }^{1}$, Michael Evans ${ }^{1}$, Julia Kay ${ }^{1}$, Laura Trupin ${ }^{1}$, Gabriela Schmajuk ${ }^{1}$, Michelle A Petri ${ }^{2}$, Jinoos Yazdany ${ }^{1} .{ }^{1}$ University of California San Francisco, San Francisco, United States of America; ${ }^{2}$ Johns Hopkins University, Baltimore, United States of America

Background: The risk of retinal toxicity and subsequent visual loss from hydroxy chloroquine (HCQ) is dependent on daily dose and duration of use. Although further efficacy and safety studies are required to understand optimal dosing strategies, real-world application of existing American Academy of Ophthalmology (AAO) recommendations in a population-based sample of patients with rheumatic disease has never been described.

Objectives: The objectives of this study were to assess application of AAO dosing recommendations across the U.S. and identify patient and practice-level risk factors for receiving higher than recommended doses using data from the ACR's RISE registry

Methods: RISE is a national, EHR-enabled registry that passively collects data on all patients seen by participating practices, reducing the selection bias present in single-insurer claims databases. As of December 2017, RISE held validated data from 1,257 providers in 236 practices, representing about $36 \%$ of the U.S. clinical rheumatology workforce. We included adult patients with at least one order for HCQ in 2017. For patients with multiple orders, the most recent order was included in the analysis. We excluded weights that appeared to be outliers and practices with $<30$ patients receiving HCQ. Instructions were interpreted to yield an average daily dose per patient. We investigated practice-level and state-level variation by calculating the proportion of patients who received a dose $>5 \mathrm{mg} / \mathrm{kg} /$ day by practice and the proportion of patients who received a dose $>6.5 \mathrm{mg} / \mathrm{kg} /$ day (AAO's 2011 recommendation) by state. We tested whether prescribing a dose exceeding the AAO recommendations was associated with patient-level demographics (age, sex, race/ethnicity, insurance) or practice characteristics (type, size) using multivariate mixed-effects regression.

Results: We included 49,712 patients (85\% female, $53 \%$ Caucasian, with mean age $57 \pm 15$ ) from 96 practices (34\% single specialty group practice, $76 \%$ with $1-5$ providers). The patient average daily dose of $\mathrm{HCQ}$ ranged from $57 \mathrm{mg}$ to $800 \mathrm{mg}$, with a median of $400 \mathrm{mg}$. Overall, $40 \%$ and $9 \%$ of patients received a HCQ dose $>5 \mathrm{mg} / \mathrm{kg} /$ day and $>6.5 \mathrm{mg} / \mathrm{kg} /$ day, respectively. Practice-level variation ranged from $6-66 \%$ for receiving a dose $>5 \mathrm{mg} / \mathrm{kg} /$ day (Figure 1 ) and $0-28 \%$ for receiving a dose $>6.5 \mathrm{mg} / \mathrm{kg} /$ day. State-level variation was also significant $(p<0.0001$, Figure 2). After adjusting for demographics and practice characteristics, low body weight $(<78 \mathrm{~kg}$, the sample median) was strongly associated with receiving doses $>5 \mathrm{mg} / \mathrm{kg} /$ day $(+64 \%, \mathrm{p}<0.001)$ and $>6.5 \mathrm{mg} / \mathrm{kg} /$ day $(+18 \%, \mathrm{p}<0.001)$. In the same model, female gender was also associated with doses $>6.5 \mathrm{mg} / \mathrm{kg} /$ day $(+5 \%, p<0.001)$. Practice characteristics were not statistically significantly associated with receiving a higher dose.
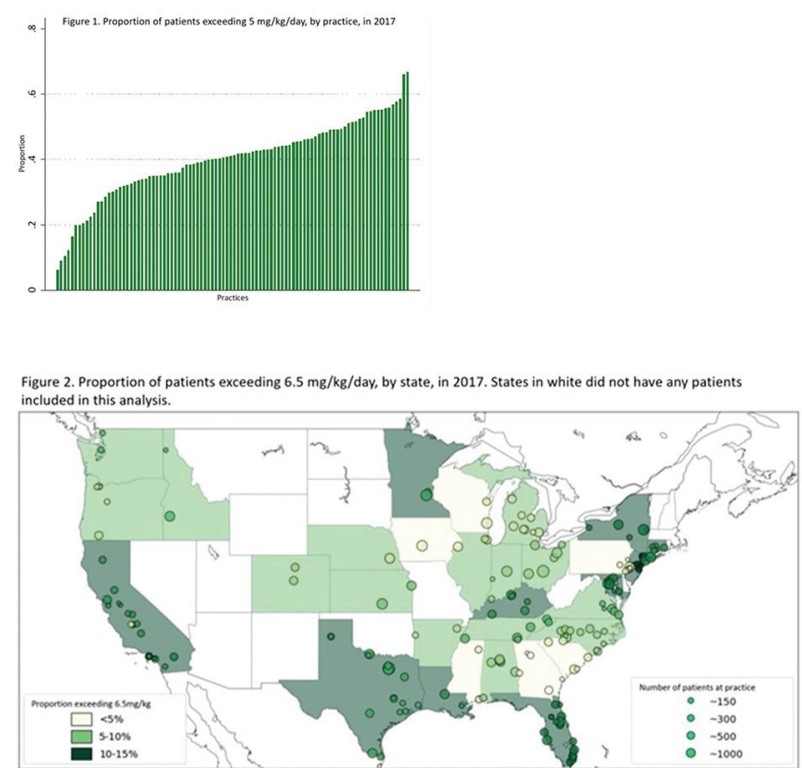

Conclusion: A significant fraction of patients with rheumatic disease on $\mathrm{HCQ}$ received doses greater than those recommended by the AAO, with large differences across practices and states. Patients with low body weight are consistently at increased risk of receiving a higher dose. Although further studies are required to 